\title{
Patient education as the basis for diabetes care in clinical practice and research
}

\author{
J.P. Assal ${ }^{1}$, I. Mühlhauser ${ }^{3}$, A.Pernet ${ }^{1}$, R. Gfeller ${ }^{2}$, V.Jörgens ${ }^{3}$ and M. Berger ${ }^{3}$ \\ ${ }^{1}$ Diabetes Treatment and Teaching Unit, Department of Medicine, WHO Collaborating Center for Diabetes Education, and \\ ${ }^{2}$ Department of Medical Psychology and Psychiatry, University of Geneva, Geneva, Switzerland; \\ ${ }^{3}$ Department of Metabolism and Nutrition, University of Düsseldorf, Düsseldorf, FRG
}

Key words: Patient education, diabetes care, metabolic control, complications.

Despite the obvious improvements made in the field of diabetes therapy during this century [1] the quality of diabetes care has, in general, remained poor. The widespread failure to acknowledge the impact of patient education appears to evolve as the primary reason for this unsatisfactory situation. Despite the firm and well founded recommendations put forward by some of the pioneers of modern diabetology, e.g. Drs. E.P.Joslin and R.D. Lawrence in the $1920 \mathrm{~s}$, it has taken almost 50 years for the beneficial effects of patient education to have finally and unequivocally been proven. The recently developed strategies for a global approach to diabetes therapy which combines biomedical, psychosocial and educational elements represents an exemplary therapeutic model for the care of many chronic diseases.

\section{The complexities of diabetes and of diabetes care}

The metabolic manifestations of diabetes mellitus oscillate from hypoglycaemia to hyperosmolar or ketoacidotic decompensation and coma. The long-term complications of the disease may involve almost all organs with disabling consequences from benign dysaesthesia of the legs to the total loss of pain sensation with the severe risk of foot lesions; from background diabetic retinopathy without any impairment of visual function to proliferative diabetic eye disease leading to blindness; from potentially reversible microproteinuria to endstage kidney failure; and from minor arterial insufficiency of the lower limbs to gangrene and amputations. The threat of acute and long-term complications as well as the need for daily monitoring (blood or urine glucose levels, foot care, blood pressure, etc.) represent a considerable psychological stress to diabetic patients and their families.

Treatment of metabolic disturbances and care of diabetic patients are not simple. There are numerous factors involved in the control of blood glucose levels. Although the underlying cause of the disease is an endocrine disorder (i. e. the absolute or relative lack of insulin secretion and/or the insensitivity to insulin at the level of the liver and some peripheral tissues), many additional factors play important roles in regulating the level of glycaemia in diabetic patients. These include the nutritional status of the patients, their dietary habits, their emotional constitution and way of coping with the disease, their familial, professional and social environment and many others. There is a constant interaction between these factors, most of which keep fluctuating extensively even within the same day. Thus, physicians and patients often find it difficult to identify the factor(s) which might have been responsible for a deterioration of metabolic control. Because the majority of these factors are closely related to the patients' behaviour, it appears evident that the achievement of longterm metabolic control is the consequence of a complex process simultaneously involving psychosocial, endocrine, and pharmacological factors. Obtaining (near)normalization of glycaemia may require the patient to perform blood glucose self monitoring several hundred times throughout a year. These measurements are, however, hardly useful in improving metabolic control unless the patients have learned to translate the results of their metabolic self monitoring into appropriate insulin dose adjustments, adaptations of diet, and other elements of therapy. The prescription of a dietary regimen will necessarily interfere with the pleasures of eating and the emotional satisfaction associated with many social or family gatherings. The presence of long-term complications may drastically reduce patients' professional and social activities; e.g. the lack of hypoglycaemia awareness may necessitate even more frequent blood glucose determinations and a more strict timing of meals. Often it is a difficult challenge for physicians to identify, together with patients, which of the spider- 
web of factors interfering with the quality of life are the most important and easiest ones to correct.

While the correction of acute metabolic complications (i. e. hyperglycaemic or hypoglycaemic comatose states) by standardized therapeutic strategies has been proven to be quite successful, the effective prevention of these metabolic crises represents a considerably more complex, as yet unresolved challenge, as it relies not only on the availability and the competent performance of physicians; rather, even more so, it relies on the diagnostic evaluation and appropriate therapeutic actions of patients. Such an active participation of patients in the treatment of their disease becomes only possible if two basic prerequisites are met: (a) appropriate information and training for patients and (b) personal motivation and active acceptance of the disease by patients.

The prevention of the long-term complications is yet another example of the complexity of diabetes care. Clear distinctions must be made between the prevention of microangiopathy and neuropathy through persistent (near-)normalization of glycaemia (secondary prevention) and attempts to prevent or postpone their disabling consequences such as blindness and/or amputations, once these complications have already developed (tertiary prevention). Although (near)normal blood glucose levels appear to be the basis for prevention of these long-term complications, once proliferative retinopathy or kidney failure are established, strict blood glucose control may no longer be indicated. At this stage of the disease, patients might be strongly motivated to strive for normoglycaemia whilst physicians focus on normalization of blood pressure and foot care (tertiary prevention), placing somewhat less emphasis on blood glucose control. This re-orientation of diabetes treatment is often difficult to accept by patients. Honest and clear information about such changes in the goals of diabetes care need to be given (repetitively) to patients at this difficult stage; the complexity of the situation should also be discussed in depth with the entire health care team.

\section{The history of patient education in clinical diabetology}

In most chronic diseases the major part of the treatment is carried out by the patients themselves in collaboration with their physicians. Monitoring of glucosuria had already been recommended to patients with diabète gras in order to follow the success of their diet- and exercise-based therapy by the French physician Bouchardat in 1875 [2]. In 1919, E. P. Joslin [3] wrote in the introduction to his book "A Diabetic Manual for the Mutual Use of Doctor and Patient" that "the manual ... has been ... simplified with the ... purpose to make it serve as text-book for the physician to use in the education of his patients". A whole chapter was devoted to "Questions and Answers for the Diabetic Patients". Within 2 years of the introduction of insulin, Joslin stated that every insulin-treated patient had to be properly educated to carry out his therapy [4]. Based upon disappointing experiences with some of his very first insulin-treated patients (some of whom had discontinued their insulin injections after having been discharged from the hospital), Joslin pointed out that any insulin therapy was "a waste of time and money unless the patient was thoroughly instructed to manage his own case" [5]. In 1925, Lawrence edited a manual on "The Diabetic Life: Its Control by Diet and Insulin. A Concise Practical Manual for Practitioners and Patients" [6] and wrote in its introduction "it is the object of this book to bring modern treatment of diabetes by diet and insulin within the scope of the general practitioner and the understanding of patients whose intelligent cooperation is necessary for the best results". As early as the 1920s, systematic efforts were made to establish diabetes education programmes for the training of insulin-treated patients. Joslin created the diabetes nurse educator and the diabetes wandering nurse, specialists who delivered the educational programmes in the hospital and at the homes of the patients, respectively [7].

It will remain an interesting phenomenon why it has taken diabetology such a long time to recognize the fundamental importance of patient education as an integral part of diabetes care. Towards the late 1970s, at last, the evidence in favour of patient education programmes has become overwhelming: Miller [8], Davidson [9], and Moffitt [10] have proven the efficacy of diabetes teaching and treatment programmes (DTTP) in reducing the frequency of acute metabolic deteriorations and their various sequelae on a large scale. As (near-)normalization of glycaemia is now being generally accepted as the principal measure of secondary prevention in diabetes mellitus, the success in achieving this therapeutic goal will obviously depend to a major part on the patient, hence his education, training and motivation "to manage his own case [5]". The strict normalization of metabolic control has been proven to have a major impact for the outcome of diabetic pregnancies; persistent normoglycaemia in these patients on an ambulatory basis can only be achieved through comprehensive educational programmes [11]. Likewise, the safe use of insulin pump delivery systems depends primarily on proper training of the patient. This represents a prerequisite for the success of this particular therapy [12]. In fact, the importance of patient education concerning the prevention of acute complications has gained such a degree of public approval that an increasing number of cases have become recently known in which physicians have been sentenced for not having formally informed and educated their patients about the potential risks of insulin treatment. On the other hand, patient education has also been proven to play a crucial role as a tertiary preventive measure in patients with the diabetic foot syndrome, as the necessity for below-knee amputations in these patients decreased most substantially both in At- 
lanta [9] and Geneva [1] as a result of a systematic programme of patient education.

Another factor which has facilitated the recent gain of support for patient education is the concern of public health authorities over the exploding costs of patient care - since it is most obvious that DTTPs can represent extremely cost-effective elements in the care of diabetes mellitus. Jönsson has attempted to evaluate the total cost of diabetes care for Sweden [13] where direct costs (hospitalizations, out-patient consultations, drugs and self monitoring materials) represented only $43 \%$ of the total financial burden to the society while the remaining $57 \%$ were indirect costs accounted for by the decrease of productivity due to absenteeism from work due to intercurrent illnesses, crippling complications such as amputations and blindness, etc. It was of note that in this study the actual cost of diabetes therapy (i.e. the expense for specific drugs and self control materials) represented only $25 \%$ of the total cost attributed to diabetes care. In the USA, the Center for Disease Control in Atlanta has been commissioned by the US Congress to develop comprehensive diabetes control programmes in 20 Federal States. A variety of intervention measures, including patient education, are currently being evaluated [14].

Finally, it should be mentioned that patients themselves are developing an increasing interest and desire to learn about their disease and to participate more actively in its treatment. Like other chronic diseases, and probably for our societies in general, the individual strives for more independence and personal involvement and rights during the decision making processes which are relevant for the course of his life, such as defining the goals and the strategies for the treatment of his diseases. These natural tendencies for the individual to emancipate himself from hitherto habitual authoritarian structures (such as a paternalistic doctor-patient relationship) have manifested themselves in the massive support for self-help groups and civil initiatives in many areas of our societies.

Never in the history of clinical diabetology has there been such an unequivocal body of evidence proving the importance of patient education in diabetes treatment and overall care. Yet patient education is still being disregarded by clinicians at large, and rarely incorporated systematically into the structures of diabetes care.

\section{Impediments to the integration of patient education into health care programmes}

Obviously, it is a difficult task to organize an integrated health care system in which the medical team devotes equal emphasis to the biomedical and educational aspects of treatment. Interviews with many heads of diabetes units carried out by one of us (JPA) during the past 15 years have revealed how arduous it was for these physicians to identify the specific difficulties which they had encountered. The reasons which they put forward for their inability to establish a DTTP (although they ac- knowledged the necessity for it) were often vague and unspecific, such as "our administration is not interested in patient education", "my diabetic patients are not motivated", or "my coworkers do not understand the importance of a team approach". However, the real problems seemed to be related to the fact that, during chronic phases of diabetes, individual treatment goals are often difficult to define for a given patient and that the eventual success of a (new) therapeutic strategy can only be evaluated during long-term follow-up. Thus short-term (and often short-lived) gratifications, such as those achieved during the treatment of acute metabolic complications, do not exist as an immediate reward and motivation for the physician. Several difficulties may stand in the way of the permanent provision of a DTTP as the basis for health care delivery in diabetes mellitus. These problems might be encountered at any level of people or structures involved in the health care system. It should be useful at this point to summarize them in brief.

The ability and motivation of patients to learn about their disease and to assume an active role in its treatment is closely related to their particular health beliefs, their personality structure, their actual psychosocial situation, the presence of disease- and/or treatment-related symptoms, the prognosis of their disease(s), and their ability to cope with and actively accept their disease. Physicians may not be inclined or able to motivate their patients for self-care because their own medical school training was predominantly biomedical and their hospital training was largely restricted to crisis intervention; furthermore, many physicians (consciously or subconsciously) object to sharing knowledge with patients as this may result in having to give up authority, power and financial benefits; others are not prepared to tolerate mistakes made by patients during the self management of their treatment, although similar mistakes committed by physicians are quite readily excused. Also, many physicians are not prepared to work as just one partner in a team of health care providers or within a treatment partnership together with the patient. Obviously, physicians are aware of the almost total lack of financial, institutional or academic rewards associated with patient education activities. Most important appears to be the almost total unawareness amongst physicians of the need for specific training in patient education. Different problems may arise on the level of the health care team where imprecise job descriptions for various team members (nurses, dietitians, physicians and others), as well as differences in the information given by various members of the team to the patient, may severely interfere with an effective educational process. Finally, the discontinuity of personnel, especially due to the rotation schemes organized for physicians in large hospitals, tends to disturb a continuous quality of diabetes education and care. Rather substantial difficulties originate frequently from problems related to the interdisciplinary team approach to diabetes education and care. Thus, an efficient cooperation between the various biomedical, psychological, social and educational specialists may be 
hampered, for example, by differences concerning the time periods during which therapeutic successes might be achieved; traditionally oriented physicians are often impatient and tend to expect more rapid solutions to medical problems. Within the interdisciplinary approach characteristic of the education and care of chronic diseases, a rather extensive overlap between the functions and duties of the various members of the health care team is necessary. Specific skills in the management and coordination of the interdisciplinary team have to be developed in order to cope with various interactions within the team and with patients. Finally, there are still many difficulties with regard to the establishment of DTTPs on the level of public health authorities. Although there are great differences between various countries (e.g. with West German governmental and insurance agencies lending substantial support and encouragement to diabetes education), certain difficulties appear to be quite common. The public health system therefore, has the tendency to support short-term rather than long-term health care programmes, despite the often expressed necessity to foster preventative medicine programmes. Often public health officers and administrators are hesitant to apply locally the experiences made with patient education programmes in other countries and ask for documentations of the costbenefit ratios of such programmes under local conditions before giving their support.

The difficulties and impediments are manyfold and they exist at every level of the health care chain. The complexity of the problem might well explain why the recommendations to establish patient education programmes as the basis for any long-term successful diabetes therapy made many decades ago have been hardly accepted by physicians and health care organizers at large.

\section{Patient education programmes}

There are many different, effective systems to educate and train patients for the treatment and care of their diabetes. Thus far, the possible alternatives are largely determined by the clinical setting locally available. In the majority of instances, therefore, patients have no choice in selecting the structure of an education programme which accommodates their particular needs and preferences. Alternative educational programmes, as developed recently, have particular advantages and limitations.

\section{Inpatient versus out-patient education programmes}

In-patient education facilities, such as a hospital diabetes center, may provide excellent teaching opportunities such as well equipped classrooms and lectures given by (para-)medical staff at defined hours. The structured organization of such DTTPs is mandatory in order to enable patients to follow the training courses for care of their disease undisturbed by allegedly urgent medical examinations (such as medical consults, $x$-ray examina- tions, angiogramms etc.). It needs to be emphasized that the education programme represents an integral part of the treatment. In fact, any effective intervention to improve the degree of metabolic control would have to rely on the provision of a systematic educational programme.

A most efficient way to provide out-patient educational programmes is the day-care-center approach: patients come to the center for the whole day in order to follow courses, participate in discussions about diet and the rules for self-regulation of insulin dosages; the reliability of their methods for metabolic self-monitoring is checked, they eat together in groups with the dietitians, and medical services (e.g. ophthalmoscopy, foot care, blood pressure readings, urine analyses etc.) are provided, if necessary.

\section{Person-to-person versus group educational programmes}

One of the traditional hallmarks of medical practice has always been the person-to-person relationship between the patient and his physician. For patient education, such a relationship offers the advantages of individualisation and the possibility of a sustained interactional process on a personal basis. However, such a system is time-consuming, the number of patients who can be admitted to the programme is strictly limited and in many busy diabetes clinics or hospital units it becomes, therefore, self-defeating. In any case, such a system of individual patient education requires a rather systematic approach by the educator - be it the physician, the nurse educator or the dietitian - in his daily practice. Education of the patient must not be left haphazard, e.g. dependent on the time and goodwill of the educator, or offered only to those patients who ask for the respective information and training. Actually, person-to-person educational programmes have to be particularly well structured. An individual check-list comprising the various topics to be addressed and discussed should be used for each patient. During each consultation, a certain period of time needs to be devoted specifically to continuing diabetes education. A systematic evaluation of the item discussed during the preceeding appointment should be part of each patient visit. Such check lists are instrumental in ensuring that all aspects of patient education necessary for the self care of diabetes have been included in the treatment of each individual patient, even though such an educational process may be stretched out over long periods of time and delivered by several diabetes educators and physicians.

Group instruction and discussion programmes have the two main advantages that a number of patients (up to approximately 10 patients) can be taught simultaneously and that an interactional process among the patients can take place. Sharing experiences with other patients greatly helps patients cope with the disease. Group teaching for patients should, however, not be organized according to the classical school model, with an ever active teacher addressing his passive students; but the diabetes educator has to (learn to) assume the role 
of a group moderator. Effective group education requires thorough preparation and prior appraisal of the personal and medical histories of the patients in the group. It is quite useless (even potentially harmful) for a physician or diabetes educator to walk into a classroom of patients previously not known to him and just to give his usual lecture. The diabetes educator, be it the physician, a nurse or a dietitian, needs elaborate educational training [15] and considerable medical knowledge and experience before any effective group teaching programme can be delivered to diabetic patients.

\section{The Diabetes Education Study Group (DESG) of the European Diabetes Association: an international experience at the European level}

During its annual meeting in 1977 at Geneva, the European Association for the Study of Diabetes (EASD) organized a 1-day symposium on patient education. The meeting drew a most surprisingly high number of attendees, and revealed the urgent need for patient education and for new strategies of diabetes care. At the time, it became apparent that the general introduction of educational aspects into clinical practice would necessitate major efforts in a number of directions. In this context, detailed information about the particular needs of the medical profession for patient education and the respectively new structures of care were required. It was for this purpose that the EASD formed the Diabetes Education Study Group (DESG) in 1979. One of the first activities of the DESG was to compile an inventory of difficulties encountered with patient education in the various countries and regions of Europe [16]. This inventory was established during a series of 6 workshops with a total of 133 diabetologists and 31 nurses/dietitians originating from 23 different European countries who were, as a group, responsible for more than half a million diabetic consultations per year. The four main difficulties concerning diabetes education in daily practice as identified by this international group of diabetes experts were (1) poor patient motivation, (2) lack of specific training for patient education, (3) organizational difficulties with regard to the integration of patient education into traditional hospital or clinic structures, (4) lack of methodologies and data on the (long-term) evaluation of the efficacy of diabetes education programmes. Both physicians and nurses/dietitians were equally concerned about the problems of traditional doctor-patient relationships and their consequences for the long-term quality of diabetes care. Based upon this inventory of problems and needs, a five year action programme was planned by the DESG outlining the following objectives:

\section{Establishment of a list of health care providers actively involved in diabetes education and care as well as a catalogue of diabetes centers providing patient education as a part of their routine management}

As of May 1985, 798 individuals and 276 diabetes centers have been registered. Two thirds of the individual membership are physicians, the remaining being nurses, dietitians, as well as psychologists and educators with the number of diabetic patients active in the development and organization of educational programmes constantly increasing. Initially, mainly physicians were included for two reasons. Without any doubt, physicians remain responsible for diagnosis and treatment of the disease, and diabetes education must never be dissociated from them. Furthermore, it was the impression that physicians had the greatest influence in convincing local hospital administrators, public health officers and/ or nurses in organizing and supporting patient education programmes. More recently, however, at least in the Federal Republic of Germany, a good deal of motivation and pressure to establish DTTPs originates from patient self-help groups and/or health insurance companies. About one fourth of the registered diabetes centers include structured patient education programmes in their daily clinical routine. Such programmes could be identified in every European country, including $\mathrm{Al}$ bania. The centers are equally distributed between northern, central and southern European countries, with a tendency to concentrate in large cities; they have an inadequate distribution in rural areas.

\section{The organization of workshops}

The efficacy of the ever increasing number of diabetes postgraduate congresses and symposia in improving the quality of diabetes care in general must be seriously questioned. One of the manyfold reasons for their disappointingly low cost-benefit ratio might be related to the educational structure of such congresses. Learning is a complex process which requires the active participation of the student. With largely passive audiences subjected to lectures and short communications, and the failure of integrating the professional experience of each participant during postgraduate training courses, the low success rates of improving the standards of medical care by such congresses seems pre-programmed. As a consequence, the DESG has developed a particular workshop model in order to improve the interaction between the diabetologists and the participants as well as amongst the participants themselves. Furthermore, specific interactional techniques were used, such as the Metaplan method [17], to which physicians have responded particularly well. Fourteen workshops lasting between 3 and 5 days were organized for 25 to 40 participants each in Geneva and one such workshop was carried out for Eastern European countries in Bucharest (Rumania). The workshops were held in different languages, and the participating countries were grouped according to their preference for five different languages in order to avoid linguistic problems during the interactional processes. The workshop format was organized to meet the following objectives: (1) to compile a list of the specific difficulties related to diabetes education in the various countries and centers, (2) to develop mutual planning exercises to organize training programmes for physicians, nurses, dietitians 
and patients, (3) to conduct theoretical and practical training concerning the techniques and methods of patient education (these parts of the workshops were directed by a number of experts in psychology and education who had been asked to participate as consultants to the DESG), (4) to clarify the problems related to patients' and physicians' attitudes, health beliefs, and motivations. In this section, experts of psychosomatic medicine and sociologists moderated discussions on the doctor-patient relationship, problems in coping with a chronic disease, and on methods of better listening to patients. The experiences of this series of workshops was summarized in a volume on "Diabetes Education" [18]. As the workshop participants were encouraged to organize similarly structured meetings in their respective countries, a snowball phenomenon of impressive dimensions developed between 1983 and May of 1985, 51 national workshops on diabetes education were organized in 17 different European countries. All of them included nurses, dietitians, physicians, psychologists, social workers, experts in education and many diabetic patients amongst the participants.

\section{Training of diabetes educators}

Workshop participants suggested organizing postgraduate training courses and facilities for diabetes educators. In fact, the diabetes units at the Universities of Geneva and Düsseldorf have each already been accepting between 100 and 150 physicians, nurses and dietitians per year to participate as guests in their five day inpatient DTTP and other diabetes care related activities. To organize such possibilities for training diabetes educators on a broader scale, the DESG has recently published a list of 64 European diabetes centers which are prepared to accept diabetes educators (to-be) to attend at their structured DTTPs. Furthermore, the DESG has been instrumental in the development of recognized official training courses for diabetes educators; for example, the German Diabetes Association has organized a 2-month course to train nurses and dietitians as diabetes educators [15], in which the participants have to pass an examination and become eligible for associate membership in the German Diabetes Association. Similar activities have been carried out or are being planned in Switzerland, Austria, Great Britain and other European countries.

Finally, the DESG regularly publishes a Diabetes Teaching Letter which aims at rapidly distributing qualified information about innovations in teaching materials and techniques to its entire membership. The Teaching Letters are drafted by a group of 50 diabetologists, nurses, dietitians, and psychologists representing expertise and variety stemming from 17 European countries. Recent issues of the Diabetes Teaching Letter have focussed on many of the subjects and problems mentioned in this article, with particular attention to the need of balancing information according to the various groups of health care providers and the different nationalities involved in the endeavour.

\section{Evaluation of diabetes teaching programmes}

\section{Evaluation of educational methodology}

Metabolic research, to take an example from biomedicine, relies on certain well established methodologies. Validity and reliability are repeatedly evaluated before and during any meaningful investigation. The same is true for routine laboratory methods such as the simple determination of blood glucose in clinical practice. Although these requirements might not be directly applicable to the field of education, it is disturbing to realize the almost total lack of validation concerning the methodology used for patient education. Several reasons may explain this unsatisfactory situation: appropriate methodologies are often not clearly defined; the majority of physicians still believe that their educational skills are inborn, and therefore do not feel the need to be supported by education specialists; furthermore, it is hardly possible to evaluate a teacher without taking into consideration his attitude and reactions towards the students - in fact, this is one major reason why health care providers tend to avoid having their methods of patient education evaluated.

Health care programmes have frequently been evaluated despite the absence of clearly defined and unequivocal therapeutic and educational objectives. Attempts to evaluate a DTTP which was initiated without precise definitions of its educational and therapeutical goals, as well as of its methodological tools, will remain fruitless exercises.

As education is a scientific discipline and a practical challenge which extends far beyond the traditional definitions of the physician's training and his duties, there is an urgent need for closer collaboration with specialists in education, e.g. in order to formulate appropriate and reliable methods for formative evaluation and systematic improvement of diabetes teaching programmes.

\section{Evaluation of diabetes teaching and treatment goals}

Continuous formative evaluation of a methodological approach to diabetes education is essential in order to improve the teaching programme and to identify the possible causes of failure in case a programme is not successful. However, the evaluation of DTTPs must not be restricted to measuring the information transfer or to documentations of the compliance to more formal impositions on the patient, such as the request to continuously make notes in a diabetes log book, or keep regular appointments with the physician or the diabetes clinic. Such assessment would merely serve to analyse the efficacy of particular treatment tools and/or the more superficial attitudes of the patient towards them.

Diabetes education is an integral part of diabetes care and, therefore, its evaluation is equal to the assessment of the overall quality of diabetes care as such. Evaluation of the effects of an educational programme for patients is comparable to the evaluation of a drug for long-term use with regard to its bioavailability, phar- 
macokinetics, its biological activity and side effects. Both diabetes education and its evaluation have to be directed at the specific therapeutic goals of the individual patient. In general, these goals are: (a) prevention of acute complications and symptoms, (b) (near-)normoglycaemia in order to prevent the development of microvascular late complications, (c) a quality of life which is compromised by the disease to the least possible extent and (d) prevention of premature disabling consequences of long-term complications.

Unfortunately, most of the available literature on the subject has failed to document the efficacy of diabetes teaching programmes as a basic and integral part of diabetes care, but has concentrated on particular aspects of the sought-after gain in diabetes-related knowledge and skills. More substantial information has been presented in studies relating the institution of a DTTP with the incidence of acute complications in a given population of diabetic patients. In this context the important work of L. Miller, J. K. Davidson, and P. Moffitt [8-10] has to be acknowledged. These clinicians and their associates have been able to clearly document the impact of their DTTPs on the incidence of diabetic ketoacidosis as well as diabetes-related amputations and hospital admissions. Their data have proven the potential benefits of DTTPs on the long-term quality of diabetes care and on the lives of their patients. In addition, their data have demonstrated an enormous saving of health care costs.

Unfortunately, these earlier publications were unable to include the more recently introduced $\mathrm{HbA} 1 \mathrm{c}$ measurements and a record of the incidence of severe hypoglycaemic episodes in their attempts to evaluate the impact of DTTPs. Only a very limited number of studies have attempted to evaluate the long-term effect of a comprehensive DTTP on HbA1c levels in large cohorts of patients consecutively referred to a diabetes center. Mühlhauser et al. [19] were able to document the long-term improvements of $\mathrm{HbA1c}$ values up to 22 months in unselected Type 1 diabetic patients consecutively admitted to participate in a structured DTTP. Similarly promising results have been reported by Larpent and Canivet [20] and Buysschaert et al. [21] who have also used the 5-day in-patient DTTP as originally instituted at the University of Geneva which has subsequently been introduced in a large number of European diabetes centers through the influence of the DESG.

With the renewed emphasis on improving glycaemic control to prevent the development of microvascular late complications of diabetes mellitus, repeated concerns have been raised about the potentially increased risk of severe hypoglycaemic attacks associated with more aggressive modes of diabetes therapy. Any evaluation of the long-term efficacy of diabetes teaching programmes must, therefore, include an assessment of the incidence of (severe) hypoglycaemic episodes. Again, very little data have so far been published on the frequency of hypoglycaemic episodes in large numbers of insulin-treated patients despite the fact that hypoglycaemia is recognized as the most dangerous and poten- tially fatal side effect of insulin treatment. Available evidence suggests, however, that the incidence of severe hypoglycaemic episodes resulting in loss of consciousness may be at least as high as 0.54 per patient per year in a given clinic population of insulin treated diabetic patients [22]. So far no studies have been performed in order to analyze the direct effects of patient education programmes on the incidence of severe hypoglycaemic episodes. On the other hand, we have been able to document an incidence rate of severe hypoglycaemic attacks of 0.19 per patient per year in a group of 434 consecutively referred adult Type 1 diabetic patients who participated in our DTTP [23].

Gangrene and cellulitis leading to amputations are among the most incapacitating and expensive consequences of diabetic late complications. Over a 4-year period, 83 amputations were performed in diabetic patients at the University hospital of Geneva, but a $85 \%$ decrease of below-knee amputations was achieved as a consequence of a specific foot care teaching programme for diabetic patients with the diabetic foot syndrome [1]. The money saved by avoiding five belowknee amputations was equivalent to the annual salaries of the entire staff of the Geneva Diabetes Treatment and Teaching Unit - a total of 12 people.

Recently, attempts to postpone the progression of renal failure by early and aggressive treatment of elevated blood pressure have been suggested. Until now no specific teaching concepts have become available on the integration of hypertension treatment into our DTTPs.

Early diagnosis of long-term complications will help to select patients for specific education programmes directed at the prevention of the disabling consequencies of these complications. Education concerning these issues should probably be offered selectively according to the particular status of the patients.

Although generally stated in the list of therapeutic goals, the "quality of life" as influenced by a DTTP has rarely been evaluated. To assess the patients' subjective well-being, psychosocial test batteries or the recording of inhibitions of social life such as the inability to eat in restaurants [24] have been suggested.

One of the most obvious benefits of DTTPs and the resulting intensification of blood glucose self monitoring and insulin therapy and its systematic adaptation by the patient is the possibility of being more liberal with hitherto rather rigid rules concerning timing, quality and quantity of the patients' nutrition. As a consequence, well educated patients may gradually liberalize their dietary regimen associated with an intensification of their insulin therapy without risking a deterioration of metabolic control [25-27]. Furthermore, it could be shown in two matched groups of elderly patients that 36 out of $46(78 \%)$ who had participated in a structured DTTP did eat more often in restaurants or with friends at home. In the group who received only haphazard dietary instructions, only $48 \%(p<0.005)$ dared to eat outside their homes [28]. 
Finally, the participation of insulin-treated diabetic patients in sports (games and/or competitions) without any undue hazards of metabolic decompensation has become possible on a broad scale with the introduction of adequate DTTPs available to the majority of Type 1 diabetic patients.

No doubt, repetitive hospital admissions seriously interfere with an undisturbed quality of life for the diabetic patient. The repeated documentation that such hospitalisations can be quite substantially reduced by DTTPs support the beneficial effect of diabetes education on the quality of life of the patients.

The performance of long-term evaluations of the quality of care should be mandatory for every treatment of chronic diseases. At least, every diabetes center should run quality controls of its own therapeutic approach. As cumbersome as these studies may be, it is also essential to extend the systematic follow-up of the patients over a considerable length of time in order not to be misled by evanescent successes [29].

Apart from the global evaluation of the quality of diabetes care as influenced by a DTTP, particular checks on certain aspects of the educational process may be useful in improving its efficacy. For example, the evaluation of a standard teaching method has led us to discover a quite unsatisfactory outcome; in response to this particular evaluation, our patient education programme concerning blood glucose self monitoring was reorganized and intensified, with a renewed evaluation including a 1 year follow-up of the patients which rendered much improved results [30].

On a much broader base, the systematic evaluation and reexamination of patients who once participated in a center's DTTP but were later followed primarily by their respective family physicians in the framework of an evaluation protocol, can serve to identify inadequacies and to improve the educational and therapeutic strategies of a diabetes center continuously over the years. The following summary represents but an example of our efforts to evaluate the efficacy of our DTTP at the University of Düsseldorf during the past few years.

\section{Evaluation of a diabetes center: University of Düsseldorf}

Since 1978, treatment of insulin-dependent diabetic patients at the University of Düsseldorf has been organized as an in-patient 5-day DTTP. The aims and the characteristics of this training programme have repeatedly been described in detail $[19,23,31]$. Subsequently, several evaluation studies have been performed in order to assess the efficacy of the intervention and further improve the programme. Apart from continuous formative evaluation, one of the major aims was to document long-term outcome, especially with respect to metabolic control and hospital admissions. To this end, every 1 to 2 years a defined group of consecutively admitted, conventionally treated Type 1 diabetic patients were comprehensively evaluated about 1 year after their participation in the programme. The methods used for these studies and the results of one of these investigations have been published [19]. It could be shown that the DTTP resulted in a substantial long-term improvement of metabolic control and a reduction of hospital admissions.

From the beginning of the programme, the use of regular insulin was regarded as an essential component of insulin therapy because patients should be able to adapt their insulin according to daily requirements with respect to the varying intensity of physical activity or intercurrent illness. However, in 1981 only $68 \%$ of the patients used regular insulin at time of discharge from the hospital with the mean proportion of regular insulin in percent of the total daily insulin dosage being only $25 \%$ (Table 1). At that time, the diabetic diet was still very rigid with respect to daily amount, distribution and timing of carbohydrate intake. Soon patients, especially those treated with continuous subcutaneous insulin infusion (CSII), reported the possibility of abandoning these rigid diet prescriptions without losing good metabolic control $[26,27]$. Thus, step by step insulin therapy was further modified, finally aiming for a subcutaneous insulin substitution as near to physiologic insulin secretion patterns as possible. In addition, patients were motivated to adapt their (regular) insulin dosage to a more and more variable carbohydrate intake. In 1983-1984, 96\% of the patients used regular insulin at discharge from the hospital, and $95 \%$ at the follow-up examination (Table 1). The proportion of regular insulin of the daily insulin dosage increased to 48 and $44 \%$ respectively. At follow-up of the 1981 patient group, only $11 \%$ of the patients injected insulin more than twice daily, while of the patient group trained in 1983-1984, 64\% treated themselves with at least three insulin injections per day. Even though it was our general goal that these patients be treated with multiple daily insulin injections, we left it up to the patients to opt for such a therapy. In fact, at discharge $60 \%$ of the patients still administered less than three insulin injections per day. Although $58 \%$ of this patient group never visited our outpatient unit during follow-up, a considerable proportion of patients increased the number of their daily insulin injections or opted for CSII treatment, while only one patient decreased the number of daily insulin injections from 4 to 3 (Table 1).

On follow-up, HbA1c levels were significantly reduced in all patient groups investigated (Table 1). The degree of metabolic control did not differ between patients with undetectable $\mathrm{C}$-peptide values from those who still had some endogenous insulin production. The least improvement of metabolic control and the most unfavourable compliance parameters, e.g. percentage of patients keeping a diabetes log book or carrying emergency carbohydrates as well as diabetes related knowledge scores, were observed in the patient group of 1982. At that time the number of patients admitted had doubled in comparison to 1981, and the proportion of patients coming from a distance greater than $30 \mathrm{~km}$ from the diabetes center increased from $34 \%$ to $75 \%$ (Table 1). In 1983 a second teaching nurse was employ- 


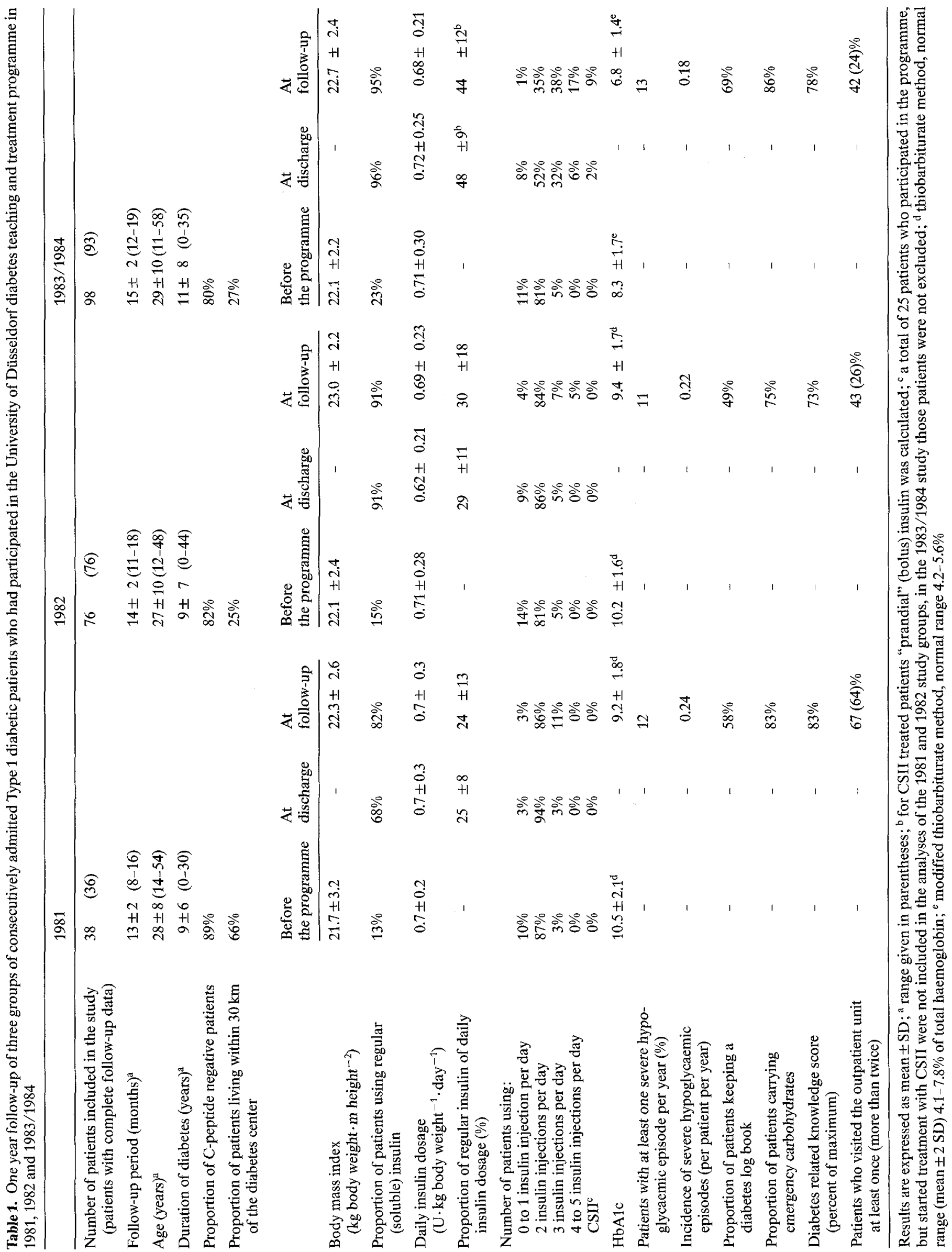


Table 2. Hospitalisations of the 1982 patient group during 22 months before and 22 months after the diabetes teaching and treatment programme $^{\mathrm{a}}$

\begin{tabular}{|c|c|c|c|c|}
\hline & $n$ & $\begin{array}{l}\text { Before } \\
\text { the } \\
\text { programme }\end{array}$ & $\begin{array}{l}\text { After } \\
\text { the } \\
\text { programme }\end{array}$ & $p$ \\
\hline \multicolumn{5}{|l|}{$\begin{array}{l}\text { Hospitalisation days per } \\
\text { patient per year: }\end{array}$} \\
\hline Total group & 62 & $16.7(3.0)$ & $6.3(1.6)$ & $<0.001$ \\
\hline $\begin{array}{l}\text { Subgroup of patients } \\
\text { with diabetic late com- } \\
\text { plications }^{b}\end{array}$ & 26 & $19.7(6.0)$ & 10.5 & NS \\
\hline $\begin{array}{l}\text { Subgroup of patients } \\
\text { without diabetic late } \\
\text { complications }\end{array}$ & 36 & $14.5(2.8)$ & $3.3(1.1)$ & $<0.001$ \\
\hline \multicolumn{5}{|l|}{$\begin{array}{l}\text { Hospital admissions per } \\
\text { patient per year: }\end{array}$} \\
\hline Total group & 62 & $0.80(0.14)$ & $0.49(0.08)$ & $<0.05$ \\
\hline $\begin{array}{l}\text { Subgroup of patients } \\
\text { with diabetic late com- } \\
\text { plications }^{b}\end{array}$ & 26 & $0.82(0.24)$ & $0.68(0.15)$ & NS \\
\hline $\begin{array}{l}\text { Subgroup of patients } \\
\text { without diabetic late } \\
\text { complications }\end{array}$ & 36 & $0.79(0.19)$ & $0.35(0.10)$ & $<0.05$ \\
\hline
\end{tabular}

Results are expressed as means (SEM); ${ }^{\text {a }}$ data were provided with the patients' informed consent from the health insurance companies where every hospital admission is registered; for 4 patients the respective insurance companies were unable to provide the data and 3 patients did not give their consent for the collection of the data; only patients with a duration of diabetes of at least 22 months before participating in the programme were included; ${ }^{\mathrm{b}}$ retinopathy and/or neuropathy and/or nephropathy; NS not significant

ed, and although the patient number admitted per year doubled again and patients did not visit the outpatient unit more frequently, the outcome of the programme on parameters of diabetes care improved.

Despite the peculiar habit of German physicians, be it in East or West Germany, to readily hospitalise their patients and keep them in the hospital considerably longer in comparison to other countries [31], the DTTP led to a substantial decrease in hospital admissions and hospital days (Table 2). Patients who had already developed diabetic late complications when participating in the training programme showed a less important reduction of hospital admissions.

The success in improving metabolic control and, at the same time, enabling patients to adopt a more flexible diet and life style in general was not associated with an unduly high risk of severe hypoglycaemic reactions either in conventionally treated patients ([23], Table 1 ) or in CSII treated patients [32]. In the 1982 patient group, the incidence of severe hypoglycaemic reactions was 0.22 per patient per year; however, the frequency of severe hypoglycaemic episodes necessitating emergency hospitalisation was as low as 0.02 per patient per year during the 22 months after the DTTP as based upon data collected from health insurance companies and hospital charts.

\section{Diabetes education - a confounding factor in clinical research?}

"Education is still too often considered as something "desirable' but not really necessary." This recent statement by L.P. Krall [33] appears to describe most appropriately the present attitudes of most practicing physicians who care for diabetic patients as well as those of many other health care providers such as public health officers. It appears, however, that this lamentable assessment might be even more relevant for the field of clinical diabetes research. During recent years a number of controversies concerning various aspects of insulin therapy have been discussed, largely without adequately appreciating one confounding factor: the degree of the patients' diabetes training.

For example, with the introduction of more intensified insulin therapies into clinical practice - be it multiple daily insulin injection or CSII therapy - repeated concerns have been raised about the potentially increased risk of severe hypoglycaemic attacks associated with these more aggressive modes of diabetes therapy.

However, incidence rates of severe hypoglycaemic episodes vary substantially between centers irrespective of whether patients are treated with CSII or insulin injections. In conventionally treated patients the incidence rates for severe hypoglycaemia vary between 0.04 [34], 0.17 [35], 0.19 [23] and 0.54 or more [22] episodes per patient per year. The available data are comparably heterogenous between CSII treated groups of patients. In the Kroc Study [36], 6 of the 34 CSII treated patients experienced a total of 9 severe hypoglycaemic episodes during the first 8 months of treatment. White et al. [37] reported an incidence rate as high as 1.2 episodes of severe hypoglycaemia per patient per year during CSII treatment, whereas others communicated incidence rates as low as 0.07 [35] and 0.13 [32]. These discrepancies about the incidence rates of severe hypoglycaemic episodes in the patient groups from various diabetes centers cannot merely be explained by differences in the degree of glycaemic control, impaired hormonal counterregulation to hypoglycaemia, the insulin regimens used or definitions of severe hypoglycaemia.

Although, for example, the use of excessive insulin dosages or the loss of hypoglycaemia related symptoms in some patients may undoubtedly render it more difficult to prevent the development of severe hypoglycaemic episodes, the quality and quantity of appropriate patient education plays a crucial role with regard to the risk of severe hypoglycaemia in a given population of diabetic patients. Thus, the lack of appropriate training of the patient (and/or his physician) to prevent severe hypoglycaemic episodes during a particular insulin treatment strategy appears to be more important than the particular instrument used for the subcutaneous substitution of insulin. Even with the introduction of insulin pumps, the occurrence of severe hypoglycaemic episodes was almost exclusively due to mismanagement 
on the part of untrained patients (and/or inexperienced physicians) rather than a consequence of malfunction of the insulin infusion devices $[32,38]$. In addition, the excessive frequency of nocturnal hypoglycaemia reported in some studies on CSII treated patients [37] may well be due to lack of adequate patient education with regard to the appropriate dosage of the basal insulin infusion rate and its appropriate adaptation by the patients $[32,38,39]$. The comparatively low incidence of severe hypoglycaemic episodes in centers focusing primarily on patient education as the basis for any form of diabetes care appears to signify that the adequate information of the patient (along with appropriate insulin dosages) is a more reliable safeguard against severe hypoglycaemic episodes than subjecting the patients to screening test procedures for hypoglycaemia (un-) awareness and counterregulation of as yet hypothetical significance.

In this context it is of note that Polonsky et al. [40] were unable to identify patients with a history of attacks of severe hypoglycaemia by assessing counterregulatory metabolic and hormonal responses to induced hypoglycaemia. They realized that "although deficient counterregulatory hormonal responses are important in the pathogenesis of hypoglycaemic reactions, other factors in the daily lives of such patients also play a major part in determining whether reactions will occur." Obvious$1 y$, in selecting their patients they did not take into account the level of the patients' training (and not even insulin therapy) as a confounding factor, since the "relevant clinical information" on their patients only included age, sex, duration of diabetes and glycosylated haemoglobin values. This study is but one example of the neglect of patient education as a decisive factor of the risk of complications associated with insulin therapy. Consequently, any meaningful assessment of hypoglycaemic episodes as a side effect of various insulin replacement strategies must be restricted to studies involving patients well trained to prevent, to recognize and appropriately treat hypoglycaemic reactions.

Similarly, education and training of the patient are essential for the prevention of diabetic ketoacidosis. Previous studies $[8,9]$ have already proven that patient education is a fundamental determinant of the incidence of diabetic ketoacidosis in a given population, independent of the strategy of (insulin) therapy used. Recent data on the incidence of diabetic ketoacidosis in Type 1 diabetic patients may vary from 0.05 [41] to 0.15 [35] per patient per year during CSII treatment and 0.12 [35] during conventional insulin therapy. It appears likely that these marked differences in the incidence rates of diabetic ketoacidosis are causally related to the ability of patients to early recognize and to abort the development of these severe metabolic deteriorations by appropriate therapeutic measures. It seems of little value to report, for a given population of diabetic patients with an already extraordinarily high rate of diabetic ketoacidosis, that a change to a more complex insulin treat- ment strategy (e.g. from conventional subcutaneous insulin injections to CSII) results in an even higher incidence of diabetic ketoacidosis [35]; the high incidence rates are presumably due to a primary lack of adequate patient education. Thus, in Type 1 diabetic patients whose treatment was based upon a comprehensive DTTP, the incidence of diabetic ketoacidosis (defined as an acidotic hyperglycaemic decompensation necessitating emergency hospitalisation, as in [35]) was 0.03 per patient per year in 76 conventionally treated patients (1982 group of Table 1 ) and equally 0.03 per patient per year in 114 CSII treated patients [32].

Following the widespread introduction of $\mathrm{HbA} 1 \mathrm{c}$ determinations as a long-term assessment of glycaemic control, it became apparent that the vast majority of Type 1 diabetic patients was in less than good, and quite often in rather unsatisfactory metabolic control. Unfortunately, this observation seems quite valid to date, especially if one examines the most often small cohorts of Type 1 diabetic patients described in the context of clinical investigations. Absurdly, some of these studies aim at evaluating new tools for the improvement of diabetes therapy - e.g. the efficacy of new insulin preparations at a time when the patients studied are in regretfully poor metabolic control to begin with, something which could have most certainly been corrected, at least to a major part, by an adequate DTTP. Again, it appears essentially useless to conduct research projects aiming to evaluate new diabetes therapies and insulin treatment strategies in particular as to their potential benefits and hazards on anyone other than well trained diabetic patients.

Acknowledgements. We gratefully acknowledge the dedicated cooperation of Professor P. Dominicé (Department of Adult Education, Faculty of Psychology and Science of Education, University of Geneva), Ms. Anne Lacroix (psychologist and educationalist), Ms. Marion Stein (psychologist), Ms. M. Kreinhofer R.N., Geneva; Professor L. Hornke, Ph. D. (Department of Educational Science, University of Düsseldorf), Ms. Vera Scholz (Dipl. Paed.), Ms. Gaby Gösseringer R. D., Ms. Inge Hansen, R. D., Ms. M. Bockholt (Oeco-Troph.), and Ms. Doris Hemmann (Diabetes Educator DDG), Düsseldorf. The organization and the evaluation of the Düsseldorf diabetes treatment and teaching programme have been most substantially supported by the Peter-Klöckner-Stiftung, Duisburg, FRG.

\section{References}

1. Assal JP (1985) A global, integrated approach to diabetes - a challenge for more efficient therapy. In: Davidson JK (ed) Clinical diabetes mellitus: a problem-oriented approach. Thieme-Stratton, New York (in press)

2. Bouchardat A (1875) De la glucosurie ou diabète sucré. Paris, p 188

3. Joslin EP (1919) A diabetic manual, 2nd edn. Lea \& Febiger, New York

4. Joslin EP, Gray H, Root HF (1922) Insulin in hospital and home. J Metab Res 2: 651-699

5. Joslin EP, Shepley HR (1946) The ideal diabetic unit: of the hospital but not in it. Mod Hosp (September issue)

6. Lawrence RD (1925) The diabetic life. J. \& A. Churchill, London 
7. Joslin EP (1924) The nurse and the diabetic. New England Deaconess Hospital, Annual Report, pp 16-21

8. Miller LV, Goldstein $\mathbb{I}$ (1972) More efficient care of diabetic patients in a county-hospital setting. N Engl J Med 286: 1388-1391

9. Davidson JK, Alogna M, Goldsmith M, Borden J (1981) Assessment of programme effectiveness at Grady Memorial Hospital Atlanta. In: Steiner G, Lawrence PA (eds) Educating diabetic patients. Springer, New York, pp 329-348

10. Moffitt P, Fowler J, Eather G (1979) Bed occupancy by diabetic patients. Med J Aust 1: 244-245

11. Jovanovic L, Peterson CM (1982) Optimal insulin delivery for the pregnant diabetic patient. Diabetes Care 5 (Suppl): 24-37

12. Sonnenberg GE, Chantelau EA, Berger M (1983) Educational aspects of pump treatment in type 1 diabetic patients. In: Assal JP, Berger M, Gay N, Canivet J (eds) Diabetes education. How to improve patient education. Excerpta Medica Internat Congress Series No 624, Excerpta Medica, Amsterdam Oxford Princeton, pp 70-77

13. Jönsson B (1983) Diabetes - the cost of illness and the cost of control. An estimate for Sweden 1978. Acta Med Scand 671 (Suppl): 19-27

14. Alogna M (1984) CDC diabetes control programs - overview of diabetes patient education. Diabetes Educator 10: 32-37

15. Scholz V, Jörgens V, Kronsbein P, Mühlhauser I, Hornke L, Willms B (1984) Course for diabetes educators. Diabetes Educator 10 (Special): $80-84$

16. Assal JP, Lion S (1983) Difficulties encountered with patient education in European diabetic centers. A report of 6 workshops conducted by the DESG. In: Assal JP, Berger M, Gay N, Canivet J (eds) Diabetes education. How to improve patient education. Excerpta Medica Internat Congress Series No 624, Excerpta Medica, Amsterdam Oxford Princeton, pp 78-89

17. Schnelle W (1983) Interactional training and learning: the Metaplan method. In: Assal JP, Berger M, Gay N, Canivet J (eds) Diabetes education. How to improve patient education. Excerpta Medica Internat Congress Series No 624, Excerpta Medica, Amsterdam Oxford Princeton, pp 191-198

18. Assal JP, Berger M, Gay N, Canivet J (1983) Diabetes education. How to improve patient education. Excerpta Medica Internat Congress Series No 624, Excerpta Medica, Amsterdam Oxford Prínceton

19. Mühlhauser I, Jörgens V, Berger M, Graninger W, Gürtler W, Hornke L, Kunz A, Schernthaner G, Scholz V, Voss HE (1983) Bicentric evaluation of a teaching and treatment programme for Type 1 (insulin-dependent) diabetic patients: improvement of metabolic control and other measures of diabetes care for up to 22 months. Diabetologia 25: 470-476

20. Larpent N, Canivet J (1984) Bicentric evaluation of a teaching and treatment programme for Type 1 (insulin-dependent) diabetic patients. Diabetologia 27: 62 (Letter)

21. Buysschaert M, Lepair-Gadisseux N, Weil R, Vandeleene B, Lambert AE (1984) Influence of a diabetes education programme on the degree of knowledge, behaviour and glycaemic control of Type 1 (insulin-dependent) diabetes. Diabetologia 27: 261 (Abstract)

22. Goldgewicht C, Slama G, Papoz L, Tchobroutsky G (1983) Hypoglycaemic reactions in 172 Type 1 (insulin-dependent) diabetic patients. Diabetologia 24:95-99

23. Mühlhauser I, Berger M, Sonnenberg GE, Koch J, Jörgens V, Schernthaner G, Scholz V (1985) Incidence and management of severe hypoglycaemia in 434 adult patients with insulin-dependent diabetes mellitus. Diabetes Care 8: 268-273

Dr. J.P. Assal

Diabetes Treatment and Teaching Unit

Department of Medicine

WHO Collaborating Center

University of Geneva

CH-1211 Geneva 4

Switzerland
24. Basdevant A, Costagliola D, Lanöe JL, Goldgewicht C, Triomphe A, Metz F, Denys H, Eschwege E, Fardeau M, Tchobroutsky G (1982) The risk of diabetic control: a comparison of hospital versus general practice supervision. Diabetologia 22: 309-314

25. Chantelau EA, Schmolke B, Gösseringer G, Hansen I, Berger M (1985) Liberalisierte Diabetesdiät bei Typ-I-Diabetikern unter intensivierter Insulin-Injektionsbehandlung. Verlaufsbeobachtung über 2 Jahre. Dtsch Med Wochenschr 110: 1119-1124

26. Chantelau EA, Bockholt M, Lie KT, Broermann C, Sonnenberg GE, Berger M (1983) Diet and pump-treated diabetes: a long-term follow-up. Diabète Metab (Paris) 9: 277-282

27. Chantelau EA, Gösseringer G, Sonnenberg GE, Berger M (1985) Moderate intake of sucrose does not impair metabolic control in pump-treated diabetic out-patients. Diabetologia 28: 204-207

28. Crausaz F, Junod B, Assal JP (1985) Self care in elderly diabetics: medical and social impacts of two types of patient education programs. Proceedings of the XII. Congress of the Internat Diabetes Federation (Abstract)

29. Worth R, Home PD, Johnston DG, Anderson J, Ashworth L, Burrin JM, Appleton D, Binder C, Alberti KGMM (1982) Intensive attention improves glycaemic control in insulin-dependent diabetes without further advantage from home blood glucose monitoring: results of a controlled trial. Br Med J 285: 1233-1240

30. Mühlhauser I, Broermann C, Bartels H, Berg R, Schwarz S, Berger M (1984) Qualitätskontrolle der Blutzuckerselbstmessung bei unausgewählten Typ-I-Diabetikern. Bedeutung der Patientenschulung. Dtsch Med Wochenschr 41: 1553-1557

31. Berger M, Jörgens V, Mühlhauser I, Zimmermann H (1983) Die Bedeutung der Diabetikerschulung in der Therapie des Typ-IDiabetes. Dtsch Med Wochenschr 11: 424-430

32. Sonnenberg GE, Spraul M, Chantelau EA, Berger M (1985) Voraussetzungen, Indikationen und Risiken der kontinuierlichen subkutanen Insulininfusions-Therapie (Insulinpumpen-Behandlung). Dtsch Med Wochenschr (in press)

33. Krall LP (1985) Education: a treatment for diabetes. In: Marble A, Krall LP, Bradley RF, Christlieb AR, Soeldner JS (eds) Joslin's diabetes mellitus, 12th edn. Lea \& Febiger, Philadelphia, pp $465-484$

34. Goldstein DE, England JD, Hess R, Rawlings SS, Walker B (1981) A prospective study of symptomatic hypoglycaemia in young diabetic patients. Diabetes Care 4: 601-605

35. Mecklenburg RS, Benson EA, Benson JW, Fredlund PN, Guinn T, Metz RJ, Nielsen RL, Sannar CA (1984) Acute complications associated with insulin infusion pump therapy. Report of experience with 161 patients. JAMA 252: 3265-3269

36. The Kroc Collaborative Study Group (1984) Blood glucose control and the evolution of diabetic retinopathy and albuminuria. A preliminary multicenter trial. N Engl J Med 311: 365-372

37. White NH, Skor DA, Cryer PE, Levandoski LA, Bier DM, Santiago JV (1983) Identification of Type 1 diabetic patients at increased risk for hypoglycemia during intensive therapy. N Engl J Med 308: $485-491$

38. Sonnenberg GE, Chantelau EA, Berger M (1982) Mismanagement of insulin pumps. Diabetes Care 5: 145 (Letter)

39. Chantelau EA, Sonnenberg GE, Best F, Heding LG, Berger M (1984) Target fasting glycaemia for pump-treated Type 1 diabetics. Klin Wochenschr 62: 328-330

40. Polonsky K, Bergenstal R, Pons G, Schneider M, Jaspan J, Rubenstein A (1982) Relation of counterregulatory responses to hypoglycemia in Type 1 diabetics. N Engl J Med 307: 1106-1112

41. Bending JJ, Pickup JC (1985) Complications of insulin infusion pump therapy. JAMA 253: 2644 (Letter)

Dr. Ingrid Mühlhauser

Medizinische Klinik der Universität Düsseldorf

Abteilung Stoffwechsel und Ernährung

Moorenstraße 5

D-4000 Düsseldorf 1

FRG 